\title{
A General Practice Experiment: Technical Aid to Developing Africa
}

\author{
NORA ACHESON,* M.R.C.S., L.R.C.P.; JOHN STEVENS,*† M.A., M.B., B.CHIR., D.OBST.R.C.o.g. ; \\ IAN TAIT,* M.A., M.B., B.CHIR., D.C.H.
}

Brit. med. F., 1965, 2, 927-929

The British medical profession and successive Governments have accepted the need to help the undeveloped countries. In particular they have recognized that we have a moral commitment to assist our ex-colonial and colonial territories to develop their medical services. Unfortunately it has proved far easier to declare our good intentions than to find doctors to implement them.

For some years various medical schools and hospitals in the United Kingdom have assisted with advice, sponsorship, and secondment of personnel to selected medical centres abroad. These arrangements have produced valuable results, but they leave untouched the problem of the great shortage of generalduty medical officers. In areas where doctors are very scarce the majority of them must be prepared to act to the limit of their capacity in all branches of medicine. It is in this field that university and hospital secondments are of little use, since the future specialist cannot afford to undertake work that has little relevance to his future career.

About three years ago it occurred to us that it might be possible to leave an English general practice and go in turn to Africa to take up posts as general-duty medical officers. The idea grew suddenly from fantasy to reality when a friend, just returned from Basutoland, agreed to act as a locum. The metamorphosis was not nearly as difficult as we had feared.

This article gives an account of our experiences. It is presented in the hope that it may provoke other practices or individuals to go themselves. The need for them to do so is very great.

Our practice in England is a rural one, with three partners, centred on a small town of 3,000 . We are accustomed to the responsibilities required in running a relatively remote practice and using our non-surgical Cottage Hospital. One of us is about 60 years of age and the other two about 40 . None of us had any special skills except those gathered in junior hospital appointments and in general practice.

\section{Preliminary Difficulties}

Once having decided in principle that we would all like to try the experiment, we were immediately faced with a battery of problems. The senior of us, in view of her age, appeared an unlikely candidate for an advertised post (for medical officers retire at about 55 from Government service). Through contacts in the mission field she found work in Malawi. The two younger partners chose Swaziland, as it happened to be advertising in that week's B.M.f. There is a limit to the length of time a partner can absent himself from a practice, and we deemed 18 months to be the limit. The Ministry of Overseas Development and the Swaziland Government helpfully agreed to permit us to share the usual three-year contract, and the

* General Practitioner, Aldeburgh, Suffolk.

† Present address: Government Hospital, Mbabane, Swaziland.
Treasury allowed the increase in cost in transporting two families instead of one to Africa and back.

The L.M.C. and Executive Council raised no objection to our leaving, for we had arranged that an experienced locum would act as a temporary partner in our absence. He and his family occupied first one absent partner's house and then the other.

To Service people and doctors working overseas our subsequent arrangings and preparations would have seemed routine, but to our well-settled families it was at times an exciting and at other times an exasperating upheaval. There seemed to be no end to it. Passages, immunizations, school arrangements, the welfare of favourite plants and animals, vehicle shippings, transfers of patients' care, farewells, and, in between all these, keeping one's part of the practice going and preparing oneself for new professional problems abroad.

Few of us in British general practice to-day possess any surgical prowess, or knowledge of tropical diseases, but this should deter no one who thinks of serving abroad. The larger part of the work will be in clinical spheres which are already familiar. Other necessary skills are learnt very quickly on the job from one's local medical colleagues. In fact two of us had very little chance to take any extra training before departure, and we both found that we learnt nearly all our new skills after we had got to Africa.

\section{Skills Needed}

We know that any average general practitioner could be immediately useful in the medical conditions of Africa to-day. Nevertheless his usefulness, as well as his sense of personal satisfaction and confidence, would be enhanced by a period of suitable training before departure. There are a few important accomplishments that are so commonly needed in Africa that to go without them may mean exposing oneself unnecessarily to anxiety and embarrassment. Here, then, is our list of skills :

1. Quite the most important single asset to possess, and one that will immediately make one welcome, is the ability to give a safe anaesthetic. Wherever one chooses to work in Africa there is likely to be, to start with anyway, someone capable of emergency surgery. Apart from anaesthetizing infants, open ether is an art not to be learnt in an advanced country. This is, fortunately, less than ever necessary in Africa, where the ubiquitous and excellent Boyle's machine is almost always available. The more sophisticated volatile agents are absent. Thiopentone induction, followed by nitrous oxide, oxygen, and ether or trilene, is standard. There is no more comforting dexterity to possess than that of being able to intubate by means of a cuffed tube after scoline paralysis. To be able to do this for patients with full bellies-a frequent occurrence in emergencies-can be life-saving. It makes caesarean section safer and operations on the burnt and on those with head injuries simpler.

2. Obstetrics provides much drama. Caesarean section, preferably lower-segment, is the great life-saving procedure in African obstetrics. Before venturing abroad it would be wise to know how to perform this operation. Relearning in this way how to open and close the abdomen safely will also enable one to cope with the 
occasional surgical emergency where no surgeon with greater experience is available. Another very useful obstetric technique, which you may well already possess, is the administration of an effective pudendal block for forceps and breech deliveries. This enables one to perform these manœuvres single-handed, and avoids the risks of general anaesthesia under difficult conditions.

3. It is helpful to be able to set up a scalp-vein transfusion. African infants commonly present in advanced states of shock and dehydration. Without the capacity to rehydrate these children with intravenous fluids one is sadly impotent. It is also useful to possess a simple rule for calculating the quantities and kinds of intravenous fluids necessary for children. A safe but not elaborate rule is required which can be carried in the head. It should be based on clinical observations and not on data that need a laboratory.

4. The extraction of teeth is a necessary accomplishment in Africa. If you can get them out whole and painlessly you will be rewarded with jubilant gratitude that is very touching. So, before you go, learn to give an effective dental block, and get some tuition in tooth-pulling if you can. Sometimes the root stays behind, and some dental hints on how best to get them out will serve you well.

5. Post-mortem examinations, which are nearly always medicolegal, are an unpleasant but inevitable part of the work of a general-duty medical officer. They should not be difficult, but they can easily be made so by a clumsy technique under primitive conditions. It would be prudent to conduct a few examinations under a pathologist's guiding eye to learn how best to display the organs of the body for examination. Watching is not enough. It is surprising how hard it can be to remove the heart and lungs from the body without mutilation if you have never actually tried it for yourself.

To be able to give a safe anaesthetic, open an abdomen if you have to, put up a scalp-vein drip, extract teeth, and do a necropsy-these few things will extend your immediate usefulness very greatly. Of course they are far from being all that could be required. Indeed, one of the fascinations of the work for us has been the realization that every medical skill, from the humblest to the more exacting, will be valued and used. The range of work that is achieved, and competently achieved, under this stimulus has impressed us all. At times we have even impressed ourselves.

But, despite technical excitements, it is the wide general medical experience and medical common sense that one already has but almost always undervalues which forms the basis of your work in Africa, just as it does at home. It is also the measure of your true value as a doctor there as here.

\section{Willingness to Teach}

The business of learning or relearning the skills we have listed is not nearly as difficult as it might seem provided a little time can be spared away from the practice. One of the finest characteristics of our profession is its generous willingness

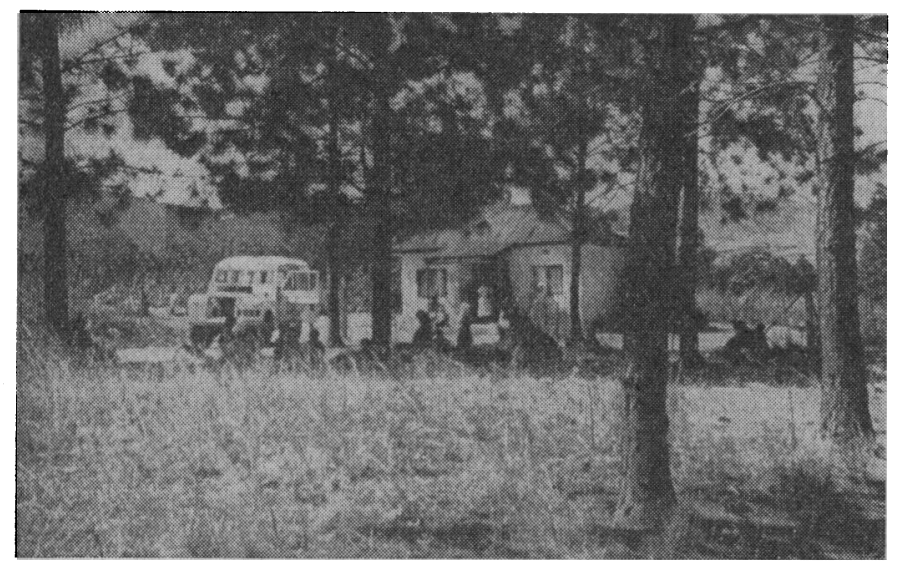

FIG. 1.-Government Farm clinic. to teach. Whatever may displease Hippocrates' ghost in the contemporary medical scene, he would surely delight that his strictures "to teach them this art, to impart precept, oral and all other instructions" are so faithfully performed in the midtwentieth century. Consultants and registrars at home and our more experienced colleagues in Africa have all been -most generous and patient teachers. They certainly have three very grateful pupils. If further recruitment of general-duty medical officers from English general practice were to be achieved we feel some help in organizing this pre-departure training should be available. It is not forbidding, and could easily be learnt by spending a concentrated few weeks in any county hospital, or a day a week and odd week-ends spread over a few months. Finally, having said all this, we feel it right to emphasize that at least $80 \%$ of what one will see and do is familiar general practice adapted to the African scene.

\section{Medical Environment}

When you have made the decision, prepared, and departed, what kind of medical environment is likely to surround you on arrival ? We can only speak from our limited experience, but conditions are likely to be very similar throughout Africa. We think we should emphasize that in many ways "colonial" medicine is easier than English general practice. We believe that few branches of our profession bear so heavily on one as general practice, with the emotional involvement and continual anxiety inseparable from trying to do one's best as a personal physician. Certain it is that in Africa one encounters many more dramatic clinical incidents ; but once a degree of facility is attained in dealing with them the battle against disease and trauma there demands rather the qualities needed for a cavalry charge than the subtleties and prolonged courage required in mounting the siege of general practice. Frustration and fatigue assailed us at times in Africa, but the satisfaction of a straightforward medical challenge successfully surmounted refreshed us far more often. To our surprise all of us have in fact experienced a marked sabbatical lifting of our cares when we had feared the reverse. We had forgotten how much in a hospital milieu a doctor is supported both by the institution and by his nursing and medical colleagues. All this more than compensated for the strangeness of new patients and new diseases, and for having once again to use one's hands in matters surgical and technical.

The medical scene in Africa presents one with a great variety of work. Ward care of the sick is the indispensable basis for good medicine there as elsewhere. It is also a good opportunity to contribute something to the teaching and training of the African nursing staff. African patients can hardly fail to capture your admiration for their stoic bravery in illness and delight you by their gay charm in convalescence. They will

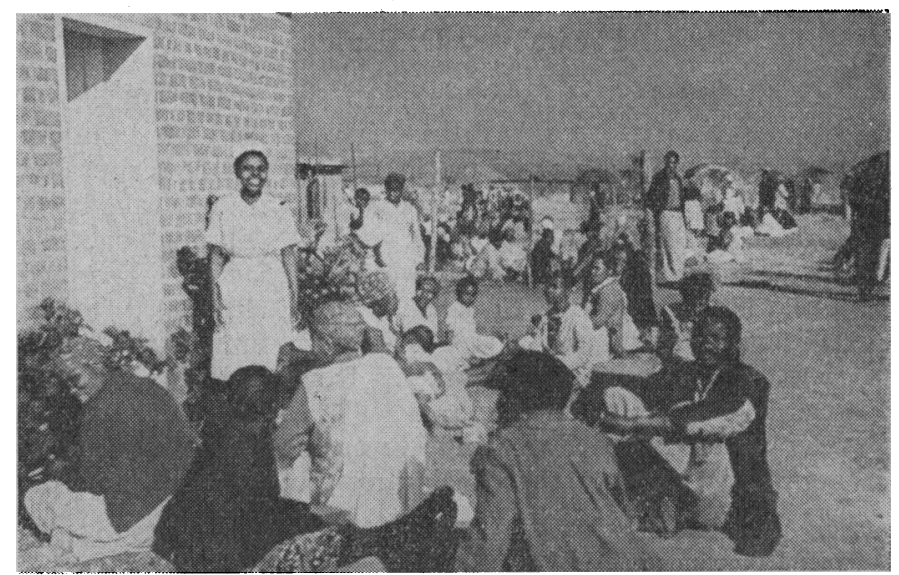

FIg. 2.-Out-patients at Mlahangatsha clinic. 
also infuriate you by their refusal to take seriously any medical advice or medication once the fear of death has left them.

Poverty, ignorance, and poor housing and hygiene are the facts of life throughout Africa. The diseases they cause, together with the damage they do each other, make up the bulk of a doctor's work.

In the field of general medicine tuberculosis and deficiency diseases are dominant in Swaziland, but malaria and other tropical disorders would join them on more equal terms in other parts of Africa. Amoebiasis, bilharzia, syphilis, typhoid, and smallpox are common. Each area will have its own snakes and parasites. It is extraordinary how soon one feels at home among these once strange complaints. It is not worth while trying to learn about them at home. Among the more sophisticated and urbanized Africans psychosomatic complaints, of ten of a colourful nature, are on the increase. Occasionally a man lies down and dies against all the prognostic rules, and it seems that only witchcraft can explain his inexorable decline to death. The true witch-doctor, or Insongoma, is now outlawed. But the African herbalist, or Inyanga, is still very active. Indeed, since he is the only easily accessible source of advice in illness for most rural Africans he is by way of being their general practitioner.

\section{Problems to be Faced}

General surgery presents familiar problems, but trauma is more evident-knife wounds, skull injuries, burns, and fractures. The latter especially are caused by contrivances unfamiliar to pastoral peoples. Tractors run over their drivers and cause terrible injuries; strange new machines cause serious damage to hands unused to working them. The new fast tarred roads take a tragic toll of lives and limbs. A dark night, an African full of beer, an 80 m.p.h. car, and a tired or welldined driver form a lethal combination.

Obstetrics is bedevilled by the absence of efficient antenatal care. Obstructed labour is very common, and so are its tragic consequences. Caesarean section is about the commonest single operation, while rupture of the uterus through a previous caesarean scar was for us a frequent occurrence. In the female ward pelvic inflammatory disease and abortions are permanent preoccupations. The African woman appears to have a wonderful capacity to withstand obstetric disaster. A patient may travel for half a day with ruptured uterus and pints of blood in the peritoneal cavity, and will still stand immediate operation on arrival at hospital.

\section{Hazards to the African Child}

The African child is blessed with a degree of charm exceeded nowhere on earth. This seems all the more surprising in view of the tribulations he faces. At birth he begins a spartan test for survival which he has about a half-and-half chance of failing. In his first year he usually has the invaluable advantage of sterile milk from his mother's breast. Even so, there are hazards enough. He will be subjected to emetics and enemas in profusion, and should he fall seriously ill these measures will be intensified in a determined effort to purge the evil from his wretched body. All too often life leaves first. Should he survive his infancy a far harder test awaits him. The arrival of the next child in the family means the withdrawal of his mother's milk, and thus all too often of all protein. Kwashiorkor then becomes the great killer, aided by any intercurrent infection of childhood.

Any children's ward in Africa must be largely filled by infants with gastro-enteritis and children with kwashiorkor. To these must be added a distressing group of children with extensive burns from accidents with fire in their kraals. Infectious diseases commonly seen are tuberculosis, pneumonia, whooping-cough, meningitis, diphtheria, measles, typhoid, and malaria.

Because of the shortage of nursing staff many African hospitals admit children with a mother or relative to feed and care for it. Night visits to the children's ward then entail picking your way over mothers sleeping on the floor, usually with their child snuggled up beside them while the cots stand empty. Such scenes are the despair of the tidy-minded but would delight the heart of the Tavistock Clinic. We might regret having to circumnavigate these sleeping forms that filled the floor space of the ward at night, but we were profoundly impressed by the psychological support these mothers gave to their, sick children.

A word should be said about the physical conditions to be found in most African hospitals. By force of circumstances these are generally very far from ideal. Poor buildings, depressing and dilapidated wards, and old and insufficient equipment are to be expected. Severe overcrowding means that usually there are more patients than beds, so that the less ill sleep on the floor. Washing and sanitary arrangements are likely to be pretty primitive. This all comes as a shock when first experienced, but we soon learned that excellent work can be done in conditions which at home one would regard as too squalid to be tolerated. One learns, too, that no one else likes it any more than you do, and that practical action to improve what you can, and adapt to what cannot be changed, is more helpful than indignation.

\section{Conclusion}

We hope that what we have written will give our colleagues at home some idea of the problems faced and the rewards enjoyed by the general-duty medical officer abroad.

For ourselves we are more than glad we went. Three facets of our experience stand out as ones we shall always value. We had the intense satisfaction of being at professional full stretch in all branches of our art. We have witnessed at first hand one of the great historical and political upheavals of mankind. And, not least, we had learned to respect a culture and people who possess a spontaneity, courage, and patience that has atrophied too far in ourselves.

\section{Summary}

Temporary expatriation from a United Kingdom general practice to take up medical appointments in Africa has proved a practical possibility. It has been a fascinating personal and medical experience for us. We think that as ordinary British general practitioners we were of value to the medical organizations we joined and to the people we went to serve. We commend our experiment to others.

We are indebted to many who helped us at various stages of our experiment. We are particularly grateful to our patients for their forbearance, and to Dr. John Briscoe for caring for them so well in our absence ; to Mr. and Mrs. Henri Marais and Dr. Jack Harvey of Malamulo Mission; and to our nursing and medical colleagues in Africa.

The Ministry of Overseas Development went to great pains to arrange our somewhat unusual contract, as did $\mathrm{Mr}$. Lucas, Clerk to the East Suffolk Executive Council.

We thank Dr. Basil Whitworth, O.B.E., Director of Medical Services for Swaziland, for permission to publish this paper. 